Dementia and Geriatric Cognitive Disorders
Dement Geriatr Cogn Disord 2010;30:309-316 DOI: 10.1159/000319896
Accepted: July 30, 2010

Published online: September 28, 2010

\title{
Large-Scale Application of a Telephone-Based Test of Cognitive Functioning in Older Adults
}

\author{
Lutz P. Breitling ${ }^{a}$ Melanie Wolf ${ }^{a}$ Heiko Müller ${ }^{a}$ Elke Raum ${ }^{a}$ Matthias Kliegel ${ }^{b}$ \\ Hermann Brenner ${ }^{\text {a }}$ \\ aDivision C070 Clinical Epidemiology and Aging Research, German Cancer Research Center, Heidelberg, and \\ ${ }^{b}$ Department of Psychology, Technische Universität Dresden, Dresden, Germany
}

\section{Key Words}

Cognitive functioning $\cdot$ Cognitive performance, remote assessment $\cdot$ Telephone-based cognitive testing

\begin{abstract}
Aims: The study of cognitive functioning in large epidemiological settings is hampered by a lack of instruments for the remote assessment of cognitive performance, especially when targeting variability across the full range of adult functioning. The present study examined the practicability of such investigations using a recently developed telephone interview (Cognitive Telephone Screening Instrument, COGTEL). Methods: A subcohort of an ongoing epidemiological study in the elderly German population (ESTHER) was interviewed via telephone by trained personnel. These data were combined with sociodemographic information obtained by standardized self-administered questionnaires, and analysed by tabulation, histograms and regression models. $\boldsymbol{R e}$ sults: A total of 1,697 interviews could be analysed. The eligible participants had a mean age \pm standard deviation of $74.0 \pm 2.8$ years. The COGTEL total scores closely followed a normal distribution with no evidence of a ceiling effect. In adjusted regression models, COGTEL total and subcompo-
\end{abstract}

nent scores were negatively associated with age and strongly positively with higher education, whereas the association with sex was less consistent. Conclusions: The results suggest that the COGTEL can readily be administered to large study populations and produces plausible and informative results. Education should be considered in all investigations using this instrument and requires further in-depth analyses. Future studies will need to elucidate its associations with risk factors and its prognostic potential for cognitive decline and dementia.

Copyright $\odot 2010$ S. Karger AG, Basel

\section{Introduction}

The decline in cognitive function in higher age, both within and beyond the limits of normal aging, presents one of the most important current challenges for health care systems and aging societies. Individuals in the grey zone between physiological age-related changes in cognitive function and dementia are not only at elevated risk of progressing to full-blown dementia, but may also experience higher mortality [1]. Elucidating predictive factors enabling early detection or even opening up avenues

\section{KARGER \\ Fax +41613061234 E-Mail karger@karger.ch} www.karger.com (c) 2010 S. Karger AG, Basel

$1420-8008 / 10 / 0304-0309 \$ 26.00 / 0$

Accessible online at:

www.karger.com/dem
Lutz P. Breitling

Division C070 Clinical Epidemiology and Aging Research

German Cancer Research Center

Bergheimer Strasse 20, DE-69115 Heidelberg (Germany)

Tel. +49 6221423 183, Fax +49 6221548 142, E-Mail L.Breitling@dkfz.de 
for preventive measures would be of considerable interest. The accumulating evidence for correlations between classical cardiovascular risk factors and cognitive disorders is of particular relevance in this regard [2].

Whereas very large epidemiological studies of cardiovascular diseases and risk factors are fairly common nowadays, a major obstacle for extending such studies to address cognitive function lies in the necessity for resource-intensive face-to-face administration of established instruments. Telephone instruments have been developed as an alternative, but assessments of their performance have mostly been restricted so far to study samples of limited size [3, 4]. Most existing instruments, for example the Telephone Interview for Cognitive Status and its modifications [5], have a focus on studying the lower end of cognitive functioning, as discussed in detail elsewhere [4]. However, in the study of determinants of cognitive functioning, telephone instruments allowing a fine-scale resolution across the range of both physiological and pathological variability of cognitive function, rather than just a screening for likely dementia [4], could potentially help to overcome the problem of small sample sizes identified by others as a key limitation responsible for contradictory results in this important field, in which relationships found in observational studies have frequently not been confirmed by the results of corresponding replication or intervention studies [6]. For example, observational epidemiological studies appeared to support a protective role of certain nutrients with respect to cognitive functioning, but randomized trials overall found no effect of nutrition-related interventions, quite possibly due to sample size limitations. Furthermore, statistical power may be poor if dementia incidence is used as an outcome in studies not designed for this purpose [6], and a - statistically more informative - continuous measure of cognitive functioning should be advantageous in such settings.

The evaluation of screening instruments for mild cognitive impairment and dementia has been identified as an important subject for further research [7]. Thus, the present article reports on the performance and large-scale application of a telephone interview for the assessment of cognitive functioning in epidemiological studies. This instrument had been designed specifically to cover a broad range of cognitive domains with appropriate resolution across the full range of adult functioning [4].

\section{Methods}

Study Population and Design

Participants of this study were a subcohort of the ESTHER study, a prospective cohort study of the elderly population in the state of Saarland in the south-west of Germany [8, 9]. In brief, 9,953 subjects aged 50-74 years were recruited from July 2000 to December 2002 by their general practitioners, to whom they presented for health screening visits. To maximize generalizability to the general elderly population, no exclusion criteria were applied except for insufficient knowledge of the German language and unwillingness or inability to participate. Data were collected applying a standardized protocol and self-administered questionnaires covering health-related information and basic sociodemographics including sex, age and education.

For the cognitive telephone assessment, participants aged $\geq 65$ years at baseline were approached during follow-up. As the present analysis was intended to describe the COGTEL (Cognitive Telephone Screening Instrument) properties across the range of the general elderly population, once again no exclusion criteria like prevalent diagnosis of psychiatric conditions were applied. The interviews were conducted in the context of the 5-year followup from May 2005 to July 2008. The study was approved by the ethics committee of the University of Heidelberg and the medical board of the State of Saarland. Both the participations in ESTHER and in the telephone interview substudy were conditional on written informed consent.

\section{Cognitive Function Assessment}

The COGTEL used has previously been described in detail [4]. In brief, COGTEL consists of 6 components covering prospective memory ( 0 or 1 point), verbal short- and long-term memory ( $0-8$ points each), working memory ( $0-12$ points), verbal fluency ( 0 to unlimited; as many words as the participant can name within a specified time) and inductive reasoning (0-8 points). The scores of the subtests can be analysed individually or combined into a weighted total score $(7.2 \cdot$ prospective memory $+1.0 \cdot$ verbal short-term memory $+0.9 \cdot$ verbal long-term memory $+0.8 \cdot$ working memory $+0.2 \cdot$ verbal fluency $+1.7 \cdot$ inductive reasoning). The individual tasks are generally taken from well-established neuropsychological instruments, such as the Wechsler scales, and COGTEL version A was used in the present study [4]. The validity of phone-based versus in-person application of this instrument has been described elsewhere, along with the concurrent validity with other variables, such as age and cognitive ability measures [4]. The interviews were conducted by study personnel specifically trained in the application of the COGTEL.

\section{Statistical Analysis}

The study population was first described according to age, sex, education (highest school qualification achieved) and major prevalent chronic disease (history of stroke or transient ischaemic attack; depression; cancer). The distribution of COGTEL subcomponent and total scores was then examined in histograms, and by tabulation of the proportion of subjects successfully giving the required answer (prospective memory) or median and interquartile range, as well as mean and standard deviation, across sex and education. Education was classified according to the major categories of school qualifications in Germany, corresponding to 
Table 1. Basic sociodemographics of study participants

\begin{tabular}{|c|c|c|c|c|c|}
\hline \multirow[t]{2}{*}{ Subgroup } & \multirow[t]{2}{*}{$\mathrm{n}$} & \multicolumn{2}{|l|}{ Men } & \multicolumn{2}{|l|}{ Women } \\
\hline & & $\mathrm{n}$ & $\begin{array}{l}\text { mean age } \pm S D \\
\text { years }\end{array}$ & $\mathrm{n}$ & $\begin{array}{l}\text { mean age } \pm S D \\
\text { years }\end{array}$ \\
\hline Overall & 1,697 & $697(100)$ & $73.9 \pm 2.7$ & $1,000(100)$ & $74.1 \pm 2.8$ \\
\hline \multicolumn{6}{|l|}{ School qualification } \\
\hline No degree & 48 & $20(3)$ & $74.3 \pm 2.3$ & $28(3)$ & $74.8 \pm 2.6$ \\
\hline 9 years & 1,155 & $418(60)$ & $73.6 \pm 2.6$ & $737(74)$ & $73.9 \pm 2.7$ \\
\hline $10-12$ years & 351 & $177(25)$ & $73.8 \pm 2.8$ & $174(17)$ & $74.8 \pm 3.1$ \\
\hline 13 years & 91 & $65(9)$ & $75.1 \pm 2.9$ & $26(3)$ & $74.1 \pm 3.1$ \\
\hline
\end{tabular}

Figures in parentheses indicate percentages.

9 ('Hauptschule'), 10-12 (various qualifications) or 13 years ('Abitur') of school education.

For simple and multiple regression analyses, markedly nonnormally distributed scores were dichotomized ( $\geq$ median versus $<$ median). These, along with the binary prospective memory subscore, were modelled using logistic regression analysis, whereas normally distributed subscores and the total score were modelled using linear regression analysis. For statistical testing, an alpha level of 5\% was applied, and SAS 9.2 (SAS Institute, Cary, N.C., USA) was used throughout.

\section{Results}

A total of 1,952 telephone interviews were conducted. Of these, 102 (5.2\%) were excluded for reasons such as premature termination of the interview, evidence for aid from another person and violation of inclusion criteria, whereas an additional 153 (7.8\%) were excluded because the interviewer had noted that deafness was present at the time of assessment (exploratory analyses had shown a strong association of deafness with COGTEL results). The joint distribution of core characteristics of the study population of the $1,697(86.9 \%)$ subjects ultimately eligible for analysis are shown in table 1. Overall, 59\% were female, and the mean age \pm standard deviation at interview was $74.0 \pm 2.8$ years. The vast majority had completed only the lowest German school qualification, and men tended to have higher education. The subjects participating in the COGTEL study were very similar in age (mean at baseline: 68.7 years) and education (2.9, 71.0, $20.8,5.4 \%$ from no to highest qualification) to those participants of the ESTHER source study who were similarly eligible but not included (69.0 years; 6.0, 74.3, 16.5, $3.2 \%)$, though these limited differences were clearly sig-

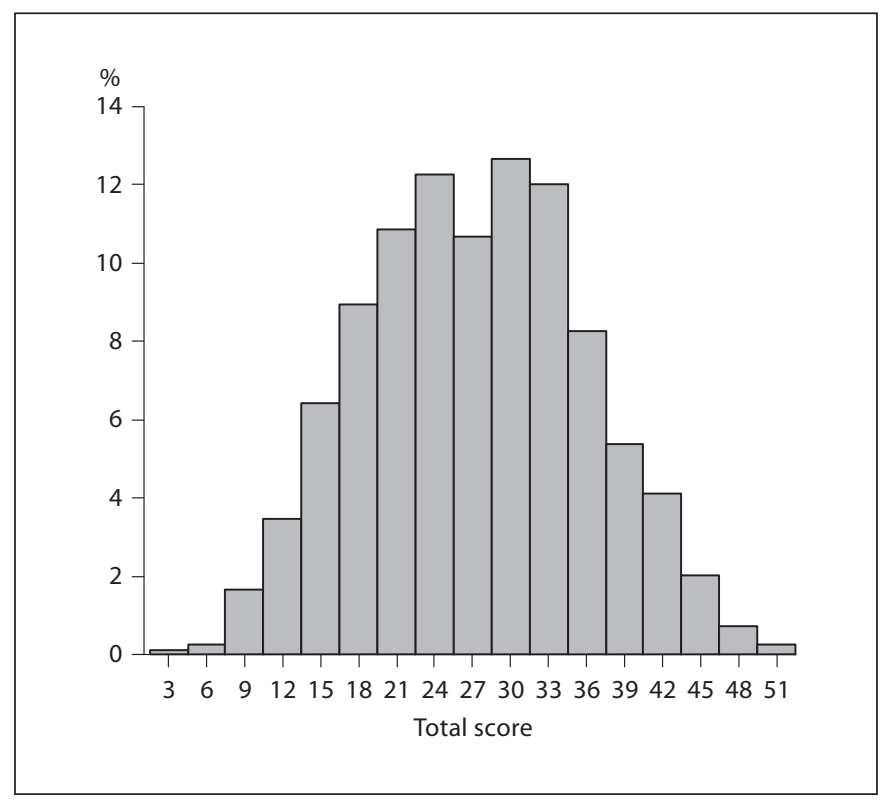

Fig. 1. Histogram of the COGTEL total score in 1,697 elderly adults in Germany.

nificant due to the rather large sample size $\left(\mathrm{p}_{\mathrm{age}}=0.008\right.$; peducation $<0.0001$ ).

The distribution of COGTEL total scores is shown in figure 1 . Their mean value was $27.1 \pm 8.7$ points. Apart from the binary prospective memory subscore, especially the results for working memory and inductive reasoning deviated markedly from a normal distribution (fig. 2) and were dichotomized for regression analyses.

The distribution of COGTEL total scores across covariables is presented in table 2 . In these analyses, there 
Fig. 2. Barplots and histograms of subscores of the 6 COGTEL items $(n=1,697)$.
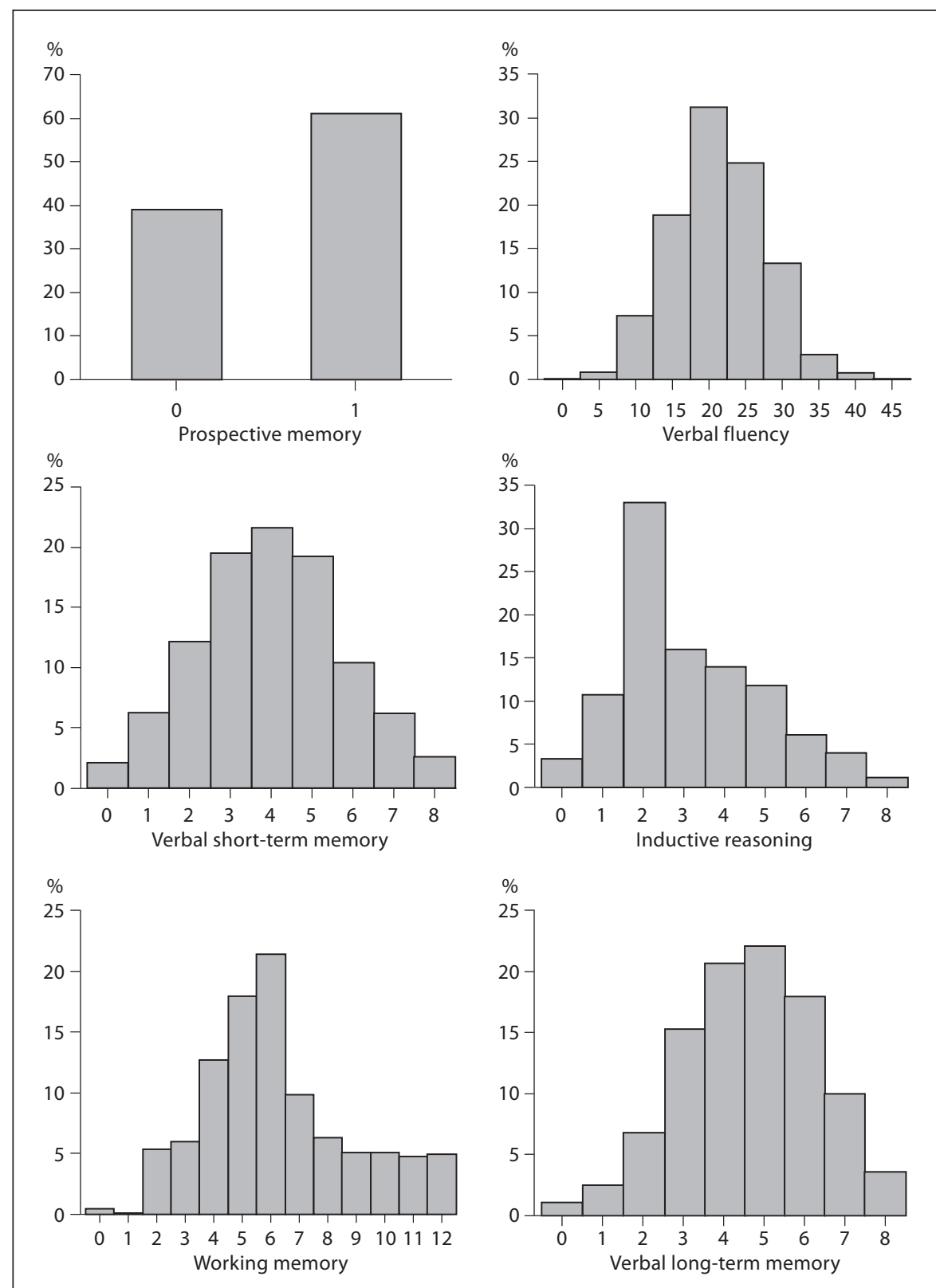

was no apparent sex difference. Test performance did not differ by cancer status. The performance appeared slightly lower in subjects with compared to those without a history of cerebrovascular disorders, but confidence intervals were strongly overlapping. The overlap was much less pronounced when differentiating by history of depression. A strong and monotonous increase in COGTEL scores was seen across increasing levels of school education. The corresponding regression analysis is presented in table 3 and revealed that male sex is significantly as- sociated with lower total scores after adjustment for age and education. The age association was quantified as a decrease by half a point per year, and the enormous differences in scores by education were confirmed. Note that neither history of cerebrovascular disorders nor depression were significantly associated with COGTEL scores or changed the results to any relevant degree when adding them to the model in table 3.

The regression analyses for the individual subscores are presented in tables 4 and 5 . Whereas age was associ- 
Table 2. Mean COGTEL scores by sociodemographics and major morbidity

\begin{tabular}{lrl}
\hline Characteristic & $\mathrm{n}$ & Total score \\
\hline Sex & & \\
$\quad$ Female & 1,000 & $27.1(26.5-27.8)$ \\
$\quad$ Male & 697 & $27.1(26.4-27.9)$ \\
School qualification & & \\
$\quad$ No degree & 48 & $22.9(20.2-25.6)$ \\
$\quad$ years & 1,155 & $26.0(25.4-26.5)$ \\
10-12 years & 351 & $30.5(29.4-31.5)$ \\
$\quad$ 13 years & 91 & $34.8(32.9-36.8)$ \\
Chronic morbidity & & \\
$\quad$ Stroke or TIA & 147 & $26.3(24.8-27.8)$ \\
$\quad$ No stroke or TIA & 1,485 & $27.4(26.9-27.9)$ \\
$\quad$ Depression & 197 & $25.8(24.4-27.2)$ \\
$\quad$ No depression & 1,441 & $27.5(27.0-28.0)$ \\
Cancer & 151 & $27.0(25.4-28.7)$ \\
$\quad$ No cancer & 1,489 & $27.3(26.8-27.8)$ \\
\hline
\end{tabular}

TIA $=$ Transient ischaemic attack. Figures in parentheses indicate $95 \%$ confidence intervals.

Table 3. Multiple linear regression analysis of age, sex and education as predictors of the COGTEL total score

\begin{tabular}{lcl}
\hline Predictor & $\beta$ & $95 \%$ CI \\
\hline $\begin{array}{l}\text { Age, years } \\
\text { Sex }\end{array} \quad-0.38$ & -0.52 to -0.23 \\
$\quad$ Female & 0 & reference \\
$\quad$ Male & -1.24 & -2.06 to -0.42 \\
School qualification & & \\
$\quad$ No degree & 0 & reference \\
$\quad 9$ years & 2.71 & 0.34 to 5.07 \\
$\quad$ 10-12 years & 7.60 & 5.12 to 10.1 \\
$\quad 13$ years & 12.4 & 9.52 to 15.3 \\
\hline
\end{tabular}

$\mathrm{CI}=$ Confidence interval. Model including all variables in the table $\left(\mathrm{r}^{2}=0.11 ; \mathrm{F}=41.5 ; \mathrm{p}<0.0001\right)$.

ated with a decrease in scores (linear regression; table 4) or lower odds of scoring high (logistic regression; table 5) in all 6 subscores, the associations with sex were more heterogeneous. The monotonous and pronounced association with education was evident in all subscores, the highest level of education being associated with more than 8 points higher scores in verbal fluency, and with more than 21-fold increased odds of above median scores in inductive reasoning.

Telephone-Based Test of Cognitive Functioning in Older Adults

\section{Discussion}

The findings presented above support the COGTEL instrument for assessing cognitive functioning as an informative and convenient device in larger-scale epidemiological studies, yielding plausible results. Few interviews had to be excluded from analyses due to practical matters possibly avoidable in much more resource-intensive faceto-face settings. The COGTEL total scores closely followed a normal distribution with no sign of a ceiling effect, which is favourable from a statistical point of view. In regression models, education emerged as a strong predictor variable, its regression coefficients being equivalent to those for tens of age years.

Whereas the general distribution and the concordance of COGTEL scores obtained by phone versus in-person interviews have been reported previously [4], the present study suggests that the administration of this instrument to large elderly study populations is a feasible undertaking. Importantly, the large number of study participants allowed us to examine the relationship between age and COGTEL more closely, despite the rather narrow age range. The earlier presentation of the instrument included a pronounced difference in score by age group, presenting a somewhat extreme contrast of subjects up to 37 or at least 59 years of age [4]. In the present study, we could describe statistically significant associations with continuous age for both the COGTEL total score and all its individual subscores. The findings also suggested that analysing the non-normally distributed subscores by appropriate statistical methods for categorical data yields consistent results.

The association of COGTEL scores with formal education was not surprising $[10,11]$, though its extent appeared remarkable. According to our adjusted regression model (table 3 ), the average difference between those with the highest versus no school qualification $\left(\beta_{13 \text { years }}=12.4\right)$ was equivalent to the average change associated with an about 30 years younger age $\left[\beta_{\text {agein years }}=-0.38 ; 12.4\right.$ / $(-0.38)=-32.6$; note that this is a strongly extrapolating and merely statistical consideration given the cross-sectional nature of our study]. Given the novel nature of the instrument used, comparability to published studies is somewhat limited. However, a study using a telephone instrument resembling the Mini Mental State Examination in the USA reported association coefficients of -4.8 for less than 8 versus 12-14 years of education, compared to -3.4 for subjects older than 89 versus $70-79$ years [12], suggesting a relative magnitude of educational versus age associations similar to our findings.

Dement Geriatr Cogn Disord 2010;30:309-316 
Table 4. Linear regression of age, sex and education with approximately normally distributed components of COGTEL (adjusted for all 3 variables)

\begin{tabular}{|c|c|c|c|c|c|c|}
\hline \multirow[t]{2}{*}{ Predictor } & \multicolumn{2}{|c|}{ Verbal short-term memory } & \multicolumn{2}{|c|}{ Verbal fluency } & \multicolumn{2}{|c|}{ Verbal long-term memory } \\
\hline & $\beta$ & $95 \% \mathrm{CI}$ & $\beta$ & $95 \% \mathrm{CI}$ & $\beta$ & $95 \% \mathrm{CI}$ \\
\hline Age, years & -0.05 & -0.08 to -0.02 & -0.22 & -0.32 to -0.11 & -0.03 & -0.06 to -0.01 \\
\hline \multicolumn{7}{|l|}{ Sex } \\
\hline Female & 0 & reference & 0 & reference & 0 & reference \\
\hline Male & -0.50 & -0.68 to -0.02 & -0.34 & -0.93 to 0.26 & -0.48 & -0.65 to -0.32 \\
\hline \multicolumn{7}{|l|}{ Education } \\
\hline No degree & 0 & reference & 0 & reference & 0 & reference \\
\hline 9 years & 0.07 & -0.43 to 0.57 & 1.94 & 0.22 to 3.66 & 0.23 & -0.24 to 0.71 \\
\hline $10-12$ years & 0.71 & 0.19 to 1.23 & 5.29 & 3.49 to 7.08 & 0.82 & 0.32 to 1.32 \\
\hline 13 years & 1.57 & 0.96 to 2.18 & 8.60 & 6.52 to 10.7 & 1.32 & 0.74 to 1.89 \\
\hline
\end{tabular}

$\mathrm{CI}=$ Confidence interval. $\mathrm{r}^{2}$ values of the 3 models were $0.06(\mathrm{~F}=21.3 ; \mathrm{p}<0.0001), 0.10(\mathrm{~F}=36.8 ; \mathrm{p}<0.0001)$ and $0.05(\mathrm{~F}=16.6 ; \mathrm{p}<0.0001)$, from left to right.

Table 5. Logistic regression analysis of age, sex and education with dichotomized components of COGTEL (adjusted for all 3 variables)

\begin{tabular}{|c|c|c|c|c|c|c|}
\hline \multirow[t]{2}{*}{ Predictor } & \multicolumn{2}{|c|}{ Prospective memory } & \multicolumn{2}{|c|}{ Working memory } & \multicolumn{2}{|c|}{ Inductive reasoning } \\
\hline & OR & $95 \% \mathrm{CI}$ & OR & $95 \%$ CI & OR & $95 \%$ CI \\
\hline Age, years & 0.94 & (0.91 to 0.98$)$ & 0.94 & $(0.91$ to 0.98$)$ & 0.95 & (0.91 to 0.98$)$ \\
\hline \multicolumn{7}{|l|}{ Sex } \\
\hline Female & 1 & reference & 1 & reference & 1 & reference \\
\hline Male & 0.88 & (0.71 to 1.08$)$ & 0.83 & $(0.67$ to 1.02$)$ & 1.25 & (1.02 to 1.54$)$ \\
\hline \multicolumn{7}{|l|}{ Education } \\
\hline No degree & 1 & reference & 1 & reference & 1 & reference \\
\hline 9 years & 1.25 & $(0.70$ to 2.24$)$ & 1.56 & $(0.87$ to 2.81$)$ & 2.17 & (1.15 to 4.09$)$ \\
\hline $10-12$ years & 2.04 & (1.11 to 3.77$)$ & 2.75 & (1.48 to 5.10$)$ & 4.76 & (2.45 to 9.23$)$ \\
\hline 13 years & 3.47 & (1.63 to 7.41$)$ & 6.17 & (2.83 to 13.4$)$ & 21.4 & (8.41 to 54.3$)$ \\
\hline
\end{tabular}

$\mathrm{OR}=$ Odds ratio; $\mathrm{CI}=$ confidence interval. Modelling 1 versus 0 (prospective memory) or at least median versus below-median points (other components). The $c$ values, i.e. concordance indices as a measure of discriminatory performance, of the 3 models were 0.58 (Wald $\chi^{2}=33.6 ; \mathrm{p}<0.0001$ ), 0.60 (Wald $\chi^{2}=49.6 ; \mathrm{p}<0.0001$ ) and 0.64 (Wald $\chi^{2}=95.6 ; \mathrm{p}<0.0001$ ), from left to right.

Previous studies had suggested complex relationships of sex with cognitive domains, which might be related to hormonal differences or interactions with genetic determinants $[13,14]$. The observation that pronounced associations with education levels might hide performance disparities between women and men (details not shown) is in line with a previous report from another region in Germany [15], suggesting that this had not been an isolated, incidental finding and could be a rather generaliz- able phenomenon that should be considered in any similar study pertaining to these birth cohorts and carried out in these parts of Germany and possibly even in the wider European region.

These discussions of education become all the more exciting if one acknowledges that it might less be formal education per se that is causally related to COGTEL performance or cognitive functioning in our (elderly) study population; rather, formal education is likely to be a 
marker for later adult life cognitive activity, both in the professional and social context, which in turn might influence and maintain cognitive functioning. The indepth analysis of more detailed pertinent data in the present cohort, as well as their placement in relation to the relevant literature [16-18], deserves comprehensive further investigation.

Some limitations of this study deserve discussion. When interpreting our results, it needs to be taken into account that the study population was a somewhat selected sample of the elderly general population, as recruitment took place during health screening visits to general practitioners. Although constitutory health insurance provides universal coverage for this examination, some self-selection at the level of examination attendance as well as consent to study participation was unavoidable. On the analytical side, the exclusion of subjects with substantial hearing problems is a double-edged sword: differences in COGTEL scores might be due to distorting differences in allocation of cognitive resources, as has been suggested, for example, for working memory tasks [19], but genuine effects of deafness on cognitive function and decline would also be plausible and indeed are an exciting field of research [20]. Dealing with this problem by restricting the current analysis to subjects in whom no sign of deafness was present was reasonably conservative for our descriptive purposes, but future longitudinal assessments of the same cohort will hopefully allow a refined and more detailed approach to related study questions. For the purpose of this primarily descriptive study, we tried to maintain high generalizability by including subjects irrespective of comorbidities of any type. As demonstrated for 3 conditions associated with structural (cerebrovascular disorders), functional (de- pression) or no immediate changes (cancer) expected to lead to worse cognitive testing performance, the differences in scores according to the presence of such conditions appeared consistent with expectations but did not affect the results to any relevant degree. Detailed analyses of associations between such participant characteristics and COGTEL scores will require treatment in separate in-depth studies.

In conclusion, the present report supported the feasibility, plausibility and informativeness of COGTEL for the phone-based assessment of cognitive functioning in elderly community-dwelling adults in Germany. The instrument thus appears to be a valuable addition to the epidemiological toolbox in cognitive research. The beneficial statistical properties of scores obtained using COGTEL suggest that it will be very useful for detailed investigations of risk and protective factors of cognitive function and decline, though - similar to other instruments in this field - educational differences in performance need to be controlled for carefully. Future efforts, including ongoing prospective components of the study presented here, will be required to elucidate the prognostic value of COGTEL scores for incident mild cognitive impairment and dementia, which might reveal potential applications in the field of screening and early preventive interventions.

\section{Acknowledgements}

This study was funded in part by the Baden-Württemberg Ministry of Research, Science and Arts. Additional funding by the Marsilius Kolleg, Center of Advanced Studies, University of Heidelberg, Germany, is gratefully acknowledged.

\section{References}

1 Guehne U, Luck T, Busse A, Angermeyer MC, Riedel-Heller SG: Mortality in individuals with mild cognitive impairment: results of the Leipzig Longitudinal Study of the Aged (LEILA75+). Neuroepidemiology 2007:29:226-234

2 Duron E, Hanon O: Vascular risk factors, cognitive decline, and dementia. Vasc Health Risk Manag 2008;4:363-381.

3 Cook SE, Marsiske M, McCoy KJ: The use of the modified telephone interview for cognitive status (TICS-M) in the detection of amnestic mild cognitive impairment. J Geriatr Psychiatry Neurol 2009;22:103-109.
4 Kliegel M, Martin M, Jager T: Development and validation of the cognitive telephone screening instrument (COGTEL) for the assessment of cognitive function across adulthood. J Psychol 2007;141:147-170.

5 De Jager CA, Budge MM, Clarke R: Utility of TICS-M for the assessment of cognitive function in older adults. Int J Geriatr Psychiatry 2003;18:318-324.

6 Coley N, Andrieu S, Gardette V, GilletteGuyonnet S, Sanz C, Vellas B, Grand A: Dementia prevention: methodological explanations for inconsistent results. Epidemiol Rev 2008;30:35-66.
7 Winblad B, Palmer K, Kivipelto M, Jelic V, Fratiglioni L, Wahlund LO, Nordberg A, Backman L, Albert M, Almkvist O, Arai H, Basun H, Blennow K, de Leon M, De Carli C, Erkinjuntti T, Giacobini E, Graff C, Hardy J, Jack C, Jorm A, Ritchie K, van Duijn C, Visser P, Petersen RC: Mild cognitive impairment - beyond controversies, towards a consensus: report of the International Working Group on Mild Cognitive Impairment. J Intern Med 2004;256:240-246. 
8 Low M, Stegmaier C, Ziegler H, Rothenbacher D, Brenner H: Epidemiological investigations of the chances of preventing, recognizing early and optimally treating chronic diseases in an elderly population (ESTHER study) (in German). Dtsch Med Wochenschr 2004;129:2643-2647.

9 Raum E, Rothenbacher D, Low M, Stegmaier $\mathrm{C}$, Ziegler H, Brenner H: Changes of cardiovascular risk factors and their implications in subsequent birth cohorts of older adults in Germany: a life course approach. Eur J Cardiovasc Prev Rehabil 2007;14:809-814.

10 Wilson RS, Hebert LE, Scherr PA, Barnes LL, Mendes de Leon CF, Evans DA: Educational attainment and cognitive decline in old age. Neurology 2009;72:460-465.

11 Scherr PA, Albert MS, Funkenstein $\mathrm{HH}$, Cook NR, Hennekens CH, Branch LG, White LR, Taylor JO, Evans DA: Correlates of cognitive function in an elderly community population. Am J Epidemiol 1988;128: 1084-1101.
12 Karlamangla AS, Miller-Martinez D, Aneshensel CS, Seeman TE, Wight RG, Chodosh $\mathrm{J}$ : Trajectories of cognitive function in late life in the United States: demographic and socioeconomic predictors. Am J Epidemiol 2009; 170:331-342.

13 O’Hara R, Miller E, Liao CP, Way N, Lin X, Hallmayer J: COMT genotype, gender and cognition in community-dwelling, older adults. Neurosci Lett 2006;409:205-209.

14 Fukai S, Akishita M, Yamada S, Hama T, Ogawa S, Iijima K, Eto M, Kozaki K, Toba K, Ouchi Y: Association of plasma sex hormone levels with functional decline in elderly men and women. Geriatr Gerontol Int 2009;9: 282-289.

15 Gerstorf D, Herlitz A, Smith J: Stability of sex differences in cognition in advanced old age: the role of education and attrition. J Gerontol B Psychol Sci Soc Sci 2006;61:P245-249.
16 Potter GG, Helms MJ, Plassman BL: Associations of job demands and intelligence with cognitive performance among men in late life. Neurology 2008;70:1803-1808.

17 Kliegel M, Zimprich D, Rott C: Life-long intellectual activities mediate the predictive effect of early education on cognitive impairment in centenarians: a retrospective study. Aging Ment Health 2004;8:430-437.

18 Virtanen M, Singh-Manoux A, Ferrie JE, Gimeno D, Marmot MG, Elovainio M, Jokela M, Vahtera J, Kivimaki M: Long working hours and cognitive function: the Whitehall II study. Am J Epidemiol 2009;169:596-605.

19 Lunner T, Rudner M, Ronnberg J: Cognition and hearing aids. Scand J Psychol 2009;50: 395-403.

20 Wallhagen MI, Strawbridge WJ, Shema SJ: The relationship between hearing impairment and cognitive function: a 5-year longitudinal study. Res Gerontol Nurs 2008;1:8086. 